\title{
O desmonte das políticas de seguridade social e os impactos sobre a classe trabalhadora: as estratégias e a resistência ${ }^{\vee}$
}

\author{
Profa. Dra. Sara Granemann *
}

\begin{abstract}
"O medo foi, afinal, o mestre que mais me fez desaprender. ...uma invisível mão roubava-me a coragem de viver e a audácia de ser eu mesmo. No horizonte vislumbravam-se mais muros do que estradas"
\end{abstract} (Mia Couto)

Meus agradecimentos às organizadoras/es pelo convite. Pela natureza dos estudos que faço na universidade pública, não tenho tido, nesta época de tantos projetos contra os direitos das trabalhadoras/es, muito tempo para estar em casa. Tenho brincado que por vezes, sinto-me uma quase caixeira viajante dos debates sobre as Propostas de Emendas Constitucionais (PEC) e outros projetos de lei, vez que, todos os dias acrescentam mais projetos ou algo do gênero que nos tornará mais explorados e com menos direitos. Os capitais e seus governos não nos dão tréguas e nem poderiam fazê-lo porque a luta por direitos - da parte dos trabalhadores - e a tentativa de sua supressão - da parte dos capitais e de seus governos - são expressões autênticas da luta de classe.

Tem sido parte da militância de dezenas de docentes - menos do que seria necessário dadas as condições de miserabilidade da classe trabalhadora brasileira - dispor os resultados de suas pesquisas realizadas, sobretudo, em universidades públicas, à disposição daqueles que produzem a riqueza social que mantém as universidades - públicas e privadas - e que, não raro, jamais a conseguem frequentar. Assim, parece-me importante que não somente o empresariado se beneficie dos conhecimentos gerados nas universidades, mas que também as lutas sociais possam se beneficiar do conhecimento produzido pela ciência. Penso que este seminário objetiva, ao propiciar a reflexão de um tema do tempo presente, juntar as necessidades da classe trabalhadora, suas demandas e lutas com as respostas que as pesquisas, a produção de conhecimento, pode ajudar a

\footnotetext{
• Palestra proferida durante o Seminário de Seguridade Social - 01 de dezembro de 2016 - Universidade Estadual de Londrina.

* Universidade Federal do Rio de Janeiro (UFRJ). Doutora. Docente na Escola de Serviço Social (ESS). Investigadora NEPEM (Núcleo de Estudos e Pesquisas Marxistas. E-mail: sgranemann@uol.com.br
} 
construir. Neste exercício, o que interessa não é somente o currículo lattes; mas, por lembrar da convocação do grande mestre Florestan Fernandes, de militância intelectual colada às necessidades da classe trabalhadora, deve nos importar, e em dias tão difíceis, como construímos o nosso currículo "luttes".

Como já foi dito aqui, vivemos tempos duros, tempos muito difíceis e, ainda bem temos a juventude - estudantes, principalmente, do ensino médio - que, no Paraná, São Paulo, Goiás, Rio de Janeiro e em tantos recantos deste enorme país, têm nos ensinado: contra os apagadores do futuro albergados no Executivos, Legislativo e Judiciário, em todos os momentos do Estado brasileiro, na política, na justiça e na economia, que a história não acabou. Reaprendemos todos os dias com estas crianças e estes jovens que, com muita coragem nos ensinam: para a classe trabalhadora, lutar é a nossa única saída! Nos ensinam e queremos tê-los conosco porque estaremos melhor se estivermos com eles e porque devemos enfrentar juntos o ataque que se quer impor sobre os jovens no que diz respeito a suprimi-lhes as aposentadorias futuras. Não apoiaremos qualquer proposta de manutenção de direito - previdenciário ou outro - que para preservar os direitos dos trabalhadores do presentes negocie o fim dos direitos das gerações futuras. Estas saídas já foram testadas em alguns países e os trabalhadores mais velhos perceberam que a sua vida, apenas por um tempo, foi garantida sobre o desemprego dos seus filhos e netos.

No aeroporto Juscelino Kubistchek, em Brasília, em um longo e muito usado corredor, um outdoor, vistoso, iluminado e enorme, recepciona os que por ali passam. Detive-me diante dele pois chocou-me pelas concisão e objetividade de sua mensagem. Emblemática, nela a Confederação Nacional da Indústria $(\mathrm{CNI})^{1}$ apresenta suas necessidades: "Reformar a previdência é essencial para a indústria". Os grandes capitais, reunidos na $\mathrm{CNI}$, possuem propostas para a aniquilação, supressão de todos os nossos direitos; dito de modo diverso, os grandes capitais articulam propostas que os governos nos diferentes poderes (Executivo, Legislativo e Judiciário) implementam para elevarem a exploração sobre todos nós, trabalhadoras e trabalhadores. Mas, para além do cartaz, temos que falar sobre o que está implícito naquele discurso.

\footnotetext{
${ }^{1}$ Conferir as propostas dos grandes capitais industriais para as contrarreformas previdenciária, trabalhista, sindical e outras, no site: http://www.portaldaindustria.com.br/publicacoes-eestatisticas/publicacoes/2016/4/29,1012/agenda-para-o-brasil-sair-da-crise-2016-2018.html As imagens da propaganda da agenda dos capitais (quase) falam por si. Consulta em outubro de 2016.
} 
É insuficiente mencionar a Emenda Constitucional 95/16 (antes PEC 55), as propostas de contrarreformas da previdência, trabalhista, sindical, sem, claramente, recusar a apologética e apocalíptica mensagem dos grandes capitais aos trabalhadores. Somam ao seu já persistente argumento de que a Seguridade Social está em crise ${ }^{2}$ o de que a crise atinge a totalidade do Estado. Sua alternativa para evitar a catástrofe final é aplicar um austero programa aos gastos públicos... destinados à classe trabalhadora! Entendamo-nos: austeridade para os capitais e seus governos eqüivale ao corte de direitos do trabalho. Somente os "gastos" estatais destinados à efetivação de direitos das trabalhadoras e trabalhadores devem ser submetidos ao austero programa. A razão para tão vulgar ataque reside na necessidade dos grandes capitais em operar uma nova partilha do fundo público que lhes permita, simultaneamente, o enfrentamento da crise e a abertura de novos espaços de inversão de seus capitais. É a sua necessidade! Resolvê-la supõe a liberação dos recursos utilizados também nas políticas sociais. Entretanto, soluções como estas somente são exequíveis se houver riqueza social concentrada no Estado sob a forma de fundo público. para se as transferir aos capitais. A mensagem acima mencionada, a um só tempo, apologética e apocalíptica oculta a existência de substantiva massa de riqueza social recolhida pelo Estado brasileiro. O Estado brasileiro não ópera com recursos escassos e nem são estes recursos pouco significativos. A "crise fiscal"do Estado é, sem rodeios, uma nova partilha do fundo público na qual a classe trabalhadora deve continuar a gerar toda a riqueza e reduzir sua já medíocre participação no usufruto da riqueza social por ela produzida e que the toca utilizar sob a forma de direitos realizados por limitadas políticas sociais. Se é certo não ser esta a única expressão da luta de classes nos dias presentes, parece-me correto dizer-se: é uma de suas manifestações centrais em todo o mundo.

No Brasil, a gravidade das medidas consubstanciadas nas contrarreformas podem revestir de opacidade o centro do debate, qual seja: como deve ser gasta a massa de riqueza social que constitui o fundo público do Estado brasileiro? Quais as prioridades para o gasto desta importante riqueza social? Aquilo que na linguagem técnica materializa os

\footnotetext{
${ }^{2}$ Ver o competente e suficiente estudo da Professora Ana Elizabete Fiúza da Motta. Cultura da Crise e Seguridade Social: Um estudo sobre as tendências da previdência e assistência social brasileira nos anos 80 e 90. SP. Cortez, 1995.
} 
"recursos monetários-financeiros" do orçamento estatal, não é outra coisa senão riqueza socialmente produzida pela classe trabalhadora, basicamente, de dois modos: 1) - por meio do trabalho excedente (extraído como mais-valia) transformado em lucro e com o qual e sobre o qual os capitais recolhem (se não o sonegam) impostos ao Estado; 2) - por meio do trabalho necessário, "cedido" pelo trabalhador ao capital em troca do salário; sobre o salário a classe trabalhadora recolhe contribuições sociais e impostos. Imediatamente e destes dois modos- em especial - mas não exclusivamente - trabalhadoras e trabalhadores são os únicos sujeitos sociais a produzir a riqueza anualmente concentrada pelos Estados, em todo o mundo. Trabalhadoras/es diante das notícias na imprensa de que os trilhões de reais (aproximadamente três) arrecadados pelo Estado brasileiro são insuficientes para o provimento de suas esqueléticas aposentadorias, pasmam diante deste abstrato e ameaçador aviso. Por sua ordem de grandeza, em geral, tais evocações - como as quantidades monetárias amealhadas nas loterias de final de ano que, para a maioria da classe trabalhadora, com vidas munidas, no máximo, em centenas de reais, sequer em milhar - são inalcançáveis.

Importa-me insistir: a austeridade que se deseja impor sobre os gastos sociais públicos restringe-se ao destinado ao direitos da classe trabalhadora; todavia, como não se pode (re)dividir o que não existe, é tão somente por existirem tais recursos e porque são enormes os capitais os desejam com volúpia.

No âmbito da Seguridade Social e, sobretudo, na política social de previdência social há que se sublinhar: as contribuições dos trabalhadores são realizadas todos os meses e por ininterruptas décadas é uma gigantesca massa de riqueza social que cada trabalhadora, cada trabalhador entrega ao Estado na sua vida presente e que opera como renúncia de melhores condições de vida para a garantia de proteção na velhice, em um momento de maior fragilidade.

A previdência social é, na história das lutas dos operários e trabalhadores sob o modo capitalista de produção, tão importante como o emprego e o salário. Somente pode prescindir de aposentadorias e pensões aqueles que detém os meios de produção.

No Brasil, a previdência social e o sistema de Seguridade Social edificados a partir da Constituição da República Federativa do Brasil em 1988, constituem o maior programa de distribuição de renda do país. Entretanto, cerca de $70 \%$ das usuárias?os do direito à 
previdência social, percebem valores que alcançam, no máximo, até três salários mínimos. Suas vidas resolvem-se em parcas unidades de milhar quando a isto chegam suas aposentadorias e pensões. Então, ganha sentido usar uma grandeza abstrata para cultivar o medo de que a proteção existente deixe de viger. O medo de uma riqueza enorme e por isto abstrata, sabemos produz-se em condições materiais objetivas e significam muita riqueza social produzida pela classe trabalhadora no Brasil.

A crise fiscal do Estado possui claros contornos: ela é a metáfora urgente de uma particularidade da exploração do trabalho entregue aos capitais pelo seu Estado, o guardião do fundo público por meio de diferentes funções que the cabe desenvolver para a garantia das condições de produção e reprodução da vida social no modo capitalista de produção.

A particularidade dos dias que correm, com a redução dos espaços temporais entre as crises econômico-políticas (e ecológica) estamos a beirar os limites da venda das mercadorias tornadas clássicas no século $\mathrm{XX}$, tais como os carros, os telefones, os computadores, o alimento e, mais grave, também na Indústria de Bens de Produção. Já conhecemos as graves denúncias de que os excedentes de produção enchem oceanos e mares, praias e ilhas pelo planeta como lugares de descarte do ultrapassado e do que não se conseguiu mercadejar. Diante da crise para que as mercadorias realizem a mais valia nela contidas são mobilizados - em simultâneo - crédito e propaganda para "aquecer" o consumo.

A previdência social no Brasil, inclusive nesta dimensão, tornou-se um importante sustentáculo do crédito (e do endividamento das) às famílias. O capital bancário-financeiro teve no crédito consignado desenvolvido sob os governos de Luis Inácio Lula da Silva e de Dilma Rousseff - em estreita articulação com o sistema de aposentadorias e pensões dos Regime Geral de Previdência Social (e executado pelo INSS), Regime Próprio de Previdência Social (RPPS) e com a folha de pagamentos da força de trabalho ativa ou em aposentadoria e pensão empregada pelo Estado brasileiro - um enorme espaço de crescimento protegido de qualquer risco. O crédito consignado de contratação desburocratizada, rápida e fácil, somente pode sê-lo porque os bancos obtiveram garantias plenas dos governos de que os contratos teriam a solidariedade do Estado que se comprometeu em repassar aos agentes bancário-financeiros as parcelas de pagamento do principal e dos juros, todos os meses, 
antes mesmo que os usuários da previdência social tivessem acesso à suas aposentadorias e pensões.

Tal medida, não apenas possibilitou ganhos de bilhões aos bancos; outra dimensão tão maléfica quanto o endividamento tornou-se possível: por terem imediatamente acesso aos recursos de que precisavam/precisam, aposentadas/os e pensionistas deixaram as ruas e as lutas que causaram importantes impactos nas décadas de 1980 e 1990, também no Brasil.

Todas as medidas já mencionadas, porém não parecem suficientes e, de fato, não o são. Urge, então, aos capitais mobilizar novas medidas pela via de seu Estado. Mesmo que momentâneas, e as soluções às crises dos capitais pelo mundo são sempre provisórias; o fundo público também ele como solução ao enfrentamento das crise dos capitais nada mais é do que uma saída transitória, conforme evidenciou-se com as Emendas Constitucionais 20/1998 do governo de Fernando Henrique Cardoso e a 41/2003 de Luis Inácio Lula da Silva e as varias medidas infraconstitucionais do governo de Dilma Rousseff.

A desconstrução dos direitos sociais amarra os diferentes ataques apresentados por várias alternativas jurídico-formais: as PEC (tanto a que se tornou EC 95/16 como a 287/16) são dimensões realizadoras do diagnóstico burguês para a crise fiscal do Estado brasileiro. A determinação primeira da EC 95/16 (antes PEC 55/16) é a seguinte: a primeira, ao fazer o congelamento dos gastos sociais, estabelece uma reorganização do uso do fundo público. Sem a reorganização do fundo público os capitais teriam dificuldades suplementares no enfrentamento das suas crises e, talvez, tivessem mais óbices no seu enfrentamento. Nunca antes, nem neste país e nem em qualquer outro lugar do mundo, o fundo público foi tão central ao "equacionamento" da crise do capital. A EC 95/16 trata desta matéria, ainda que não o diga com todas as letras. Seu imperativo: congelar o fundo público para as políticas sociais. Mas, a EC não muda só a relação com as duas políticas sociais que estão sendo mais atacadas: a saúde e a educação. A EC 95/16 altera toda a Seguridade Social (saúde, previdência social e a assistência social) e a educação.

Por que vai mudar? Porque a partir da EC - 95/16, o que nós tínhamos como gastos estabelecidos na Constituição Federal era, por assim dizer, o rodapé. O rodapé significava o seguinte: o orçamento fiscal e da Seguridade Social balizavam os mínimos aceitáveis e sobre os quais erguiam-se os gastos com direitos sociais. O espaço entre o rodapé que está 
rente ao chão, e o teto como o último horizonte possível para o alargamento dos direitos configuraria o espaço da disputa dado pela luta de classes. O rodapé, o mínimo, era apenas o patamar obrigatório para começar a política social para o atendimento do direito. Todavia, quando o o rodapé torna-se o teto - e foi isto que a EC 95/16 instituiu - temos uma considerável redução dos direitos sociais.

Convém perguntar, em que consiste a urgência em transitar do rodapé ao teto com a EC 95/16? O fundo público, em quantidades cada vez maiores, não encontraria espaço para ser vertido além dos quase $50 \%$ atuais para os donos do capital, sob a sua forma preferencial: a de dívida pública. Limita-se o valor gasto em saúde, em educação, ou o valor a ser gasto em Seguridade Social; deste modo, não teremos um mínimo definido constitucionalmente: teremos um máximo.

O Estado no modo capitalista de produção é dominação de classes. E, conta-se, teria sido a matriarca da família Rockefeller quem apresentou a melhor definição das relações do grande capital com a gestão do Estado ao seu filho quando aquele mencionouIhe que seria candidato à presidência dos Estados Unidos: "Não vai não. Isso é coisa para os nossos empregados", teria ouvido da mãe. Ela condensa o que é o Estado no modo de produção capitalista. É dominação de classe não realizada diretamente pelos capitais; quem a executa são os seus empregados.

Os empregos do grande capital, no Brasil, estão, por meio dessas várias medidas jurídico-legais, a dimensionar a partilha do fundo público. Nesta partilha, que é de trilhões de reais, uma parte deve ficar liberada para a compra de títulos públicos e para a ampliação dos negócios dos capitais que passam a mercadejar com os direitos sociais transmutados na forma de "serviços". A EC 95/16 congela os gastos com a educação, a previdência, a saúde; congela os gastos com as políticas sociais, porque no momento da crise, quando há que se priorizar o uso de seu salário, as famílias brasileiras de trabalhadores transferem seus filhos de uma escola privada para uma escola pública. Se a escola pública, incluindo as Universidades, não puderem aumentar os valores para fazer essa política social, nós vamos ter mais gente entrando nela,, só que disputando o que é menor. Claro que a qualidade cairá. E essas serão as novas mercadorias que a classe trabalhadora, melhor alocada no mercado de trabalho, passará a comprar. Ela terá que escolher entre comprar educação ou saúde. Vai ter que escolher entre comprar saúde ou previdência porque não poderá 
comprar todas as mercadorias. Mas, se conseguir comprar essas mercadorias, deixará de ter um carro, uma casa própria.

Então, o fundo público sofre uma nova partição com esses congelamentos. 0 Estado reservará a cada ano uma parte mais generosa para a transferência aos capitais, sob a forma financeirizada, e reduzirá o espaço das políticas sociais ao transformar aquilo que é de direito, e realizado pela política social, em novos espaços de investimentos de capitais.

É esse fundo público que precisa ser redimensionado. Para isso, precisa desconstitucionalizar tudo o que resta de 1988, para reverter a queda do lucro da burguesia. O uso do fundo público pelos grandes capitais operaria como uma contratendência para "resolver" momentaneamente a crise com o uso dos recursos alocados nas políticas sociais e com a abertura de novos espaços de investimentos para os capitais. Por tudo isto, para os capitais, é urgente desconstruir os direitos sociais.

Com a sua redução deixa de ter política social? Não. Até Milton Friedman e Friedrich Hayek, em seus últimos escritos concordavam que para aqueles totalmente desprotegidos havia que se promover alguma "ajuda". De que forma? Da mesma forma que a política de assistência social, o Programa Bolsa Família, com transferência de dinheiro. Transferência de dinheiro para que os mais pauperizados possam comprar as mercadorias, oferecidas pelos capitais, compatíveis com seus ganhos. O plano de saúde, por exemplo, que custa trinta reais por mês para a família e que tem pior atendimento do que qualquer hospital público. Mas, para a saúde se transformar num espaço significativo dos negócios dos capitais, deve-se, antes, assim como todas as outras políticas, degradá-la ao limite. A construção do descrédito de uma política social como a previdência pública, de um hospital público, de uma universidade pública combina, basicamente, dois ingredientes: redução do fundo público para realizar aquela política e destruição das organizações coletivas da classe trabalhadora.

É preciso derrotar a classe trabalhadora por meio da construção do descredito entre as trabalhadoras e trabalhadores sobre as organizações. Estas por sua vez, devem passar a agir em acordo com os capitais e seu Estado para que a resistência ao desmonte da política social seja minimizado. Para vergar a resistência dos trabalhadores atuam no parlamento e elaboram leis para redução de investimentos nas policias sociais que realizam 
os direitos sociais; mas, não dispensam, via executivo, a atuação e o enfrentamento direto. Na greve de 2015 aqui no Paraná, o governo de Carlos Alberto (Beto) Richa (PSDB) demonstrou como o Estado dos grandes capitais deve se portar diante da classe trabalhadora e da juventude estudantil em luta; contra ela o Estado utilizou a violência aberta, prenúncio do que passaria a ser mobilizado em todo o país.

No plano federal, há que se perguntar por que o presidente Michel Temer, uma vez consolidado o golpe jurídico-parlamentar, não encaminhou imediatamente ao Congresso Nacional a contrarreforma da previdência como anunciou que o faria, na mídia, por diversas vezes? Supomos que o governo Temer não encaminhou a reforma de imediato porque seria incômodo e poderia potencializar o desgaste de seu governo propiciada pela retomada das lutas contra a perda de direitos previdenciários.

Bem aconselhado, o governo Temer priorizou encaminhar uma PEC que estabelecesse um teto para os gastos sociais e, a seguir, a PEC 287/16 para contrarreformar a previdência no espirito do que é o essencial para os grandes capitais. Sua aposta, (a dos grandes capitais) logrou êxito: a EC 95/16 (antes Pec 55/16) de tradução mais difícil para a classe trabalhadora, não mobilizou grandes contigentes contra sua aprovação. Evidentemente, também as burocracias e aparatos sindicais, desacreditados por tantos anos de colaboração com os capitais, devem ser responsabilizados pela perda dos direitos sociais. Seja porque não tiveram ou porque não quiseram mobilizar forças para as lutas nas ruas, o programa dos capitais e de seus governos acertou na implementação de sua política ao encaminhar em primeiro lugar a EC 95/16 para limitar o uso do fundo público com direitos sociais.

No plano da organização da classe trabalhadora a contrarreforma da previdência é - quase - imediatamente compreensível; pagar mais, trabalhar mais e receber menos, é algo decifrável entre as massas trabalhadoras. Despesas, orçamentos, trilhões de reais insuficientes redução de gastos primários, são debates que exigem mais esforço e organização para sua compreensão. Se no âmbito das universidades estes temas encontram dificuldades para serem apropriados e decifrados em sua essencialidade não há que se esperar que as massas trabalhadoras, desorganizadas, afluíssem às ruas.

Embora tenha sido um acerto, do ponto de vista do capital e de seus empregados, começar pela EC 95/16, a aprovação desta lei não Ihes é suficiente. O encaminhamento da 
PEC 287/16 da contrarreforma da previdência precisa desconstitucionalizar, desconstruir os direitos, pela destruição desta política social. Se até o Ministério da Previdência pode ser extinto, não tiveram sorte diversa os capítulo, artigos, alíneas e parágrafos constitucionais que tratam da Política Social de Previdência Social dos RGPS e RPPS; neste tema, tudo já foi alterado pelas sucessivas contra-reformas previdenciárias ocorridas desde o início dos anos de 1990 e não há mais nada do texto original aprovado em 1988.

Com Fernando Henrique Cardoso a contrarreforma previdenciária resultou na Emenda Constitucional no 20/98, dirigida, sobretudo, ao Regime Geral de Previdência Social (RGPS). A principal alteração foi na exigência para alcance do direito que passou de comprovação de tempo de trabalho (serviço) para comprovação de tempo de contribuição. Ademais, por não ter conseguido aprovar todas as mudanças desejadas a regulamentação da EC 20/98 introduziu o Fator Previdenciário que impôs, em média, um aumento de 07 (sete) anos de trabalho e uma redução de 30 \% (trinta) no valor dos direitos a serem recebidos. Esta contrarreforma foi muito agressiva com os direitos da força de trabalho imediatamente empregada pelos capitais; entretanto, para os capitais ela não foi suficiente.

Em 2003, sob o governo de Luis Inácio Lula da Silva implementa-se a "isonomia às avessas" pelo rebaixamento dos direitos da força de trabalho empregada pelo Estado. Luis Inácio Lula da Silva fez da contrarreforma da previdência a sua primeira e mais brutal contrarreforma pela EC 41/03. Com ela destruiu-se uma cláusula pétrea da constituição do país: aposentados e pensionistas do serviço público federal passaram a novamente contribuir com a Previdência Social, e isso se estendeu para os regimes próprios dos estados e dos municípios. As isonomia e paridade foram extintas e instituiu-se a previdência privada como (falsa) alternativa para os trabalhadores que ingressaram no serviço público federal após sua regulamentação.

A Emenda Constitucional 41/03 foi regulamentada no sentido de entregar a vida de professores e professoras, trabalhadores e trabalhadoras do Estado brasileiro, ao mercado de capitais. Os trabalhadores, além de renunciarem parte de suas vidas diárias cai contribuírem para suas aposentadorias futuras, passam a entregar uma parte de seus salários para o mercado de capitais usá-lo e nomina-lo por "previdência complementar". 
Trabalhadores e trabalhadoras ao suporem tais investimentos por previdência não são informados, em geral, dos riscos para suas vidas decorrentes desta "escolha".

\section{O diagnóstico do Fórum de Debates sobre Políticas de Emprego, Trabalho e}

Renda e de Previdência Social, instituído ${ }^{3}$ no governo de Dilma Rousseff, consignado em cento e noventa e quatro slides, como a síntese do trabalho desenvolvido na mais perfeita tradução da conciliação de classes que incluiu centrais sindicais, com exceção da CSPConlutas, confederações dos capitais, governo e assessoria do DIEESE. O diagnóstico elaborado assume a contrarreforma da previdência como necessária porque trabalha com o argumento de que a previdência é deficitária. Dito de modo diverso, os representantes reunidos no Fórum, partiram também eles de um falso diagnóstico que de tão consensual e difundido ganha ares de verdade inquestionável a ser apresentada aos trabalhadores. Esta falsa premissa, assumida na PEC 287/16 é o eixo estruturado da contrarreforma do governo Temer como já o foi igualmente nos governos acima mencionados.

Ao estruturar o diagnóstico de que a previdência social é deficitária, o centro da contrarreforma de Temer - e de seus antecessores - não pode ser outro senão o financiamento. Em estados como o Rio de Janeiro e oRio Grande do Sul, o pacote de austeridade recolhe medidas como o aumento da contribuição dos ativos, aposentados e pensionistas, de $11 \%$ para $14 \%$. e institui, no Rio de Janeiro, uma cota extra por longo prazo. Entretanto, não há propostas dos governos para a elevação da contribuição dos empresários, do combate à sonegação, da desvinculação de receitas e das isenções milionárias vertidas aos grandes capitais.

Os parâmetros e premissas sustentares das contra-reformas da previdência dos diferentes regimes estão registrados em documento do Banco Mundial de 19944; está ali decretado: a previdência pública deve ser suficiente para combater a indigência na velhice. A tradução desta assertiva para os dias de hoje, sob a contrarreforma de Temer: desvincular o Benefício de Prestação Continuada do salário mínimo. O combate à indigência pode se realizar nos moldes e valores do Programa Bolsa Família. Todo o mais deve ser organizado como previdência complementar.

\footnotetext{
${ }^{3}$ Conforme o Decreto no 8.443, de 30 de abril de 2015 e a Portaria no 21, de 01 de setembro de2015.

${ }^{4}$ Conferir em: World Bank. Averting the Old Age Crisis: Policies to Protect the Old and Promote Growth. New York: Oxford University, 1994. Disponível em: http://bit.ly/2gcQ4Uj.
} 
Outro ponto que está contido na PEC 287/16 é o relativo ao aumento da expectativa de vida no Brasil e isto faz com que os aposentados estejam a viver mais do que deveriam. Eu menciono este argumento com ironia porque eu tenho absoluta clareza que viver mais, duplicar, triplicar o tempo de vida no espaço de um século é a mais importante conquista realizada; mais do que ter ido à lua, de ter mapeado o sol, de saber que tem água em marte. Hoje, no Brasil, as mulheres estão vivendo, em média, cinco a sete anos mais do que os homens. Chegamos perto dos oitenta anos em algumas regiões do país. Noutras, a idade média masculina não passa dos 65 anos, exata e cientificamente a idade mínima exigida para aposentadoria na proposta do governo Temer.

Esse cálculo demográfico revela o seguinte: como as pessoas estão vivendo mais, elas devem trabalhar mais, e a idade mínima para se aposentar deve ser elevada para sessenta e cinco anos. Como sabemos, ninguém recebe aposentadoria no ataúde; então, se a expectativa de vida do homem adulto é de sessenta e seis anos em Alagoas e no Maranhão, elevar a aposentadoria para sessenta e cinco anos de idade, com quarenta ou até quarenta e nove anos de contribuição, significa que as pessoas que contribuíram de múltiplas formas para a formação do fundo público usufruirão por um, dois, três, quatro, cinco anos, no máximo, de suas aposentadorias.

As mulheres, somos também "privilegiadamente" atacadas porque conquistamos - por nossas múltiplas tarefas e jornadas - o direito de uma redução de cinco anos menos de idade e cinco anos menos de contribuição que os homens, desde 1988. Continuamos a ter quatro ou cinco jornadas de trabalho. São as mulheres deste país - e quanto mais pobre, mais dura a vida - que cuidam da casa, dos filhos, dos doentes e trabalham também fora da vida doméstica e, se conseguem, estudam.

Sob o governo Dilma Rousseff - em uma iniciativa "de mulher para mulher" aprovou-se a lei 13.135 de dezessete de junho de 2015, que imputa exigências duríssimas amparadas em diagnóstico misógino e francamente dirigido contra as mulheres que, sabese, vivem mais e, com frequência, até pela permanência do machismo na vida social brasileira, casam-se com homens mais velhos. As exigências para que o cônjuge sobrevivente possa usufruir de pensão combina idade do sobrevivente e tempo de vida em comum. A partir destes requisitos criou-se uma escala de direitos muito discricionários com os casais que tenham acentuada diferença de idade entre si. 
O governo de Temer convocou os governadores para uma reunião que aconteceu há mais ou menos um mês, e a mídia pouco divulgou, para acertar o seguinte: uma gestão unitária de regime geral e dos 2.080 regimes próprios que existem, sendo 2.052 dos municípios e capitais, mais 27 estados e Distrito Federal e um regime próprio da União. Isso congrega cerca de nove milhões de trabalhadores (servidores públicos) com contribuições até 2013 , sobre a totalidade dos proventos. Esta é uma fatia muito expressiva de riqueza social condensada nos salários da força de trabalho que pode ser mobilizada pela "previdência-privada" Fazer a convergência entre os sistemas previdenciários foi uma proposta dos trabalhadores à Constituição Federal de 1988. Nós, a classe trabalhadora, queríamos um único regime, não queríamos essa separação entre o geral e os próprios. Fomos derrotados nisso porque os estados e os capitais queriam a pulverização desse dinheiro. Não havia tido ainda, em 1988, a centralização do mercado bancário financeiro, que é do governo de Fernando Henrique Cardoso em diante. Esse dinheiro, pulverizado pelos capitais em bancos estaduais inclusive, dava uma margem de mobilidade e autonomia para a utilização do fundo público para os governadores e para os prefeitos das capitais e dos grandes municípios.

Agora, alguns são ainda os mesmos atores da recusa da unificação em 1988, desejam que os regimes previdenciários operem em isonomia ; sua "isonomia às avessas"é a seguinte: tomam como referência o direito mais rebaixado e estendem para todos os demais direitos esta igualdade para baixo para que União, Estados e Municípios tenham direitos símiles. Tal convergência não significa que todos nós estaremos no mesmo sistema. Por agora, é suficiente que se estabeleçam as mesmas regras e exigências e, especialmente, os mesmos direitos rebaixados e deveres aumentados. 0 estágio mais baixo de conquistas da luta das trabalhadoras e dos trabalhadores tomada como referência para os direitos e o estágio mais alto da ofensiva do capital como referência para a subtração dos direitos da classe trabalhadora. Para sublinhar: o estágio mais alto da ofensiva capital, no qual a regra seja a mais dura para trabalhadoras/es, será a referência de isonomia de todos os regimes prevcdênciários públicos.

Na vida rural verifica-se o mais precoce ingresso na vida laboral e aos quatro/cinco anos de idade as crianças já estão envolvidas nos trabalhos domésticos e da terra e por isso chegam mais sofridos à vida adulta. Trabalhadoras/es rurais são considerados, junto aos 
trabalhadores e trabalhadoras domésticos, os responsáveis pelo déficit do regime geral da previdência. Estes trabalhadores pela natureza de seus esforços laborais, morrem precocemente e não chegam sequer a idade para usufruírem do Benefício de Prestação Continuada.

A atual contrarreforma proposta pelo governo de Temer, via PEC 287/16, diferente da que Lula e Fernando Henrique fizeram, é uma reforma contra os dois sistemas e todas as condições de trabalho da classe trabalhadora. Para que? Para abrir um espaço importante ao mercado de capitais. Estes mercados transacionam com dinheiro, seu mercado específico denomina-se mercado de capitais. A previdência, por suas características contributivas, mensal e de largo prazo, reveste-se de importância impar aos capitais. A massa de capitais ali estocados é para alguns, oportunidades de investimentos, para outros é determinação das crises e, para a classe trabalhadora, é aumento da exploração.

Renunciar todo dia a ter uma comida melhor, porque temos que pensar na velhice, e entregar uma parte do nosso salário ao Estado burguês e depois saber deste mesmo Estado que ele não nos devolverá o salário poupado sob a forma de aposentadoria porque precisa destes recursos para o socorro aos capitais é tão desesperador quanto revelador da natureza de classe (dos grandes capitais) do Estado capitalista.

Para finalizar, repetirei o que escrevi em outro texto de combate às contrarreformas para responder às trabalhadoras e trabalhadores que me indagam nestas palestras se a previdência social acabará. Respondo-Ihes: como em tantos anos, quando a classe trabalhadora se levantou, parecia aos burgueses, quase sempre, que a toupeira (as lutas da classe trabalhadora) que, silenciosamente, cava no subterrâneo já estivesse morta e putrefata. A eclosão de movimentos e de lutas de classe não ocorre, após mais de uma década de apassivamento, porque as suas lideranças desejam e chamam-na da janela para que volte a lutar. Isto supõe superar o apassivamento cultivado por longos anos. Contudo, ao contrário, do que pensam os coveiros da toupeira, ela continua a cavar e a esburacar o solo mais profundo para fazer ruir, um dia, toda a superfície.

Muito obrigada. 